\title{
Prevalence of dental caries and periodontal disease in deaf and mute children attending special schools in Jaipur city, Rajasthan
}

\begin{abstract}
Introduction: Oral health of special children is one of the sensitive issues that have been touched by very few people. An attempt has been made to assess the prevalence of dental caries and periodontal disease status in deaf and mute children.

Materials and method: A total of 257 deaf and mute children were included from the four special schools in Jaipur city. Dental caries and periodontal disease status was recorded. Data thus collected subjected to statistical analysis using frequency distribution.

Results: It was observed that $15.18 \%$ and $30.74 \%$ children had dental caries in primary and permanent teeth respectively. Community periodontal index (CPI) score revels that majority of the subjects (45.53\%) had bleeding on probing, $31.13 \%$ and $2.72 \%$ had calculus \& periodontal pocket $4-5 \mathrm{~mm}$ respectively.

Conclusion: The results of the study clearly reflect that there is a need for preventive measures to improve the oral health of these children so that we can prevent dental caries

and periodontal diseases.
\end{abstract}

Keywords: deaf and mute, dental caries, periodontal diseases, special children
Volume 7 Issue 4 - 2017

\author{
Om Prakash Yadav,' Girish R Shavi,' Manju \\ Panwar,' Shivendra Rana, ${ }^{2}$ Ravi Gupta, ${ }^{3}$ \\ Akshay Verma ${ }^{2}$ \\ 'Department of Public Health Dentistry, Rajasthan Dental \\ College and Hospital, India \\ ${ }^{2}$ Department of oral and maxillofacial pathology, Rajasthan \\ Dental College and Hospital, India \\ ${ }^{3}$ Department of Prosthodontics, Crown and Bridge and \\ Implantology, Rajasthan Dental College and Hospital, India
}

Correspondence: Omprakash Yadav, Department of Public Health Dentistry, Rajasthan Dental College \& Hospital, Jaipur, Rajasthan, India,Tel 9887298I27, Email opyadav544@gmail.com

Received: June 13, 2017| Published: June 27, 2017

\section{Introduction}

Disabilities is a wide term, covering impairments, activity limitations, and participation restrictions that hampers function of body structure, create problems in performing a task and problem in involvement in the life situations respectively. ${ }^{1}$ The term handicap has been defined as a systematic taxonomy of the consequences of injury and disease. ${ }^{2}$ Disabilities may be physical, mental, or social. Physical impairment refers to a broad range of disabilities which may be congenital or a result of injury like muscular dystrophy, multiple sclerosis, cerebral palsy, amputation or more. Deaf-mute term is used to for a person who is deaf and could not speak. ${ }^{3,4}$ Over a billion people, fifteen percent of the world's population, have some kind of disability. About 110 to 190 million adult population have significant difficulties in functioning. ${ }^{5}$ In India total disabled population is $26,810,557$. Out of these the hearing impaired children are 5,071,007. ${ }^{6}$ Deaf and Mute children are one of the major population groups of disabled children. Around one in six hundred neonates born with congenital hearing loss. ${ }^{7}$ According to a world health organization (WHO) report, the principle causes of hearing impairment in India were infections such as bacterial meningitis, mumps \& measles, negligence and ignorance. ${ }^{8}$ Deaf and Mute condition affect general behaviour, and impair social functioning. Such children often neglected due to ignorance, fear, misconception, and negative attitudes. ${ }^{8}$ Children with this disability have marked oral and maxillofacial pathologies, may be due to their actual disability or for other medical, financial or social reasons, or even because their parents find it very difficult to carry out proper daily oral hygiene. ${ }^{9}$ The prevalence of dental caries is estimated to be about $70 \%$ worldwide. ${ }^{10}$ Periodontal disease is also one of the two major dental diseases that affect mankind at highest prevalence rate. ${ }^{11}$ Periodontal diseases are one of the more prevalent oral diseases which affect more than $50 \%$ of Indian community. ${ }^{12}$ The prevalence of dental caries is approximately $60-65 \%$ in India. ${ }^{13}$ Many studies have shown a higher prevalence of dental caries and periodontal diseases among mentally and physically disabled population than their normal counterpart. ${ }^{14-17}$ Therefore it is highly necessary to protect oral health of these children from childhood as poor oral health may lead to various dental diseases like dental caries, periodontal diseases and loss of tooth. The periodontal status of special children may be compromised due to their inability to comprehend and thus comply with the oral hygiene measures. In these children periodontal disease is more prevalent, possibly as a result of an altered immune state. Almost universally plaque and gingivitis scores are higher in disabled children. ${ }^{18}$ People with disabilities deserve the same kind of opportunities as those who are without disability for oral health and hygiene. Unfortunately, care of oral health is one of the major unattended health needs of the disabled children. ${ }^{19}$ Keeping the above facts in mind and so such is conducted in this part of Rajasthan state. The present study was conducted with the aim to assess the prevalence of dental caries and periodontal diseases among deaf \& mute children attending various special schools in Jaipur city.

\section{Materials and methods}

The present cross-sectional descriptive study was conducted among children of special schools for the deaf and mute in Jaipur city. All the children in the four special schools (one government and three private) for deaf and mute in Jaipur city were included in the study.

A total of 257 children were selected based on the inclusion and exclusion criteria.

\section{Inclusion criteria}

a) Present on the day of examination 
b) Willing to participate in the study

\section{Exclusion criteria}

a) Non cooperative children

b) Children using tobacco in any form

A single examiner carried out the study and was calibrated in the department of public health dentistry of the private dental college before starting the study. The reliability was tested by using kappa statistics and observed value was .87 (Almost perfect agreement) ${ }^{20}$ Ethical approval for conducting the study was obtained from the institutional ethical committee and permission was obtained from the principal's of special schools. Informed consent was also obtained from the study parents. All the participants were prior intimated about the day and date of the study. A modified world health organization (WHO) proforma $1997^{21}$ was used to measure dental caries (dentition status index) and periodontal disease [community periodontal index (CPI) \& loss of attachment (LOA) index]. The oral examination was done in well illuminated rooms. The study subjects were made to sit comfortably on plastic chair and help was taken from the teachers and caretakers. Frequency distribution was used for analysis of data.

\section{Results}

The present study was conducted to assess the dental caries and periodontal disease status among the study deaf and mute children attending four special schools in Jaipur city. Among the total 257 study subjects 179 were males and 78 females. (Figure 1) The study subjects were of the age of 5-20 year (mean age 11.64 year) old deaf and mute children attending four special schools in Jaipur city (Table $1)$. In the present study the prevalence of dental caries was found to be $15.18 \%(0.30 \pm 0.83)$ and $30.14 \%(0.54 \pm 0.95)$ in primary and permanent teeth respectively (Table 1 ).

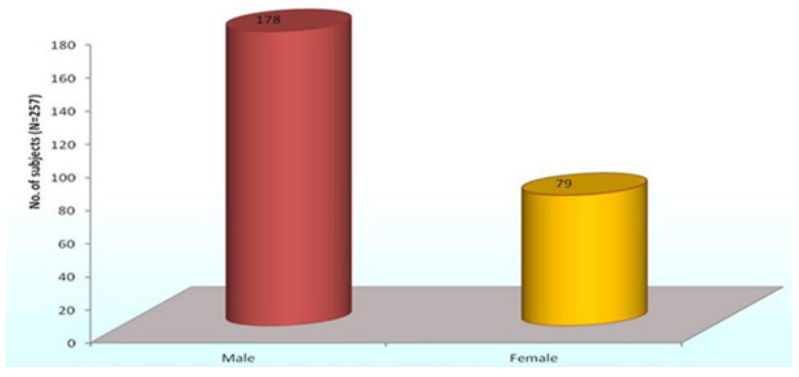

Figure I Distribution of study subjects according to gender.

Table I Descriptive parameters for age, dental caries \& fractured teeth (primary \& permanent teeth)

\begin{tabular}{ll}
\hline Parameters & Mean $(\mathbf{\pm S D *})$ \\
\hline Age & $\mathrm{I}$ I.65 (2.78) \\
No. of Primary decayed teeth & $0.30(0.84)$ \\
$\begin{array}{l}\text { No. of Permanent decayed teeth } \\
\text { No. of total decayed teeth }\end{array}$ & $0.54(0.96)$ \\
$\begin{array}{l}\text { No. of Primary Traumatic (Fractured) } \\
\text { teeth }\end{array}$ & $0.84(\mathrm{I} .22)$ \\
$\begin{array}{l}\text { No. of Permanent Traumatic (Fractured) } \\
\text { teeth }\end{array}$ & $0.08(0.3 \mathrm{I})$ \\
\hline
\end{tabular}

*Standard deviation.

\section{Dentition status in primary teeth}

Thirty nine children $(15.18 \%)$ had Dental caries in primary teeth, where as none of the children had missing teeth as a result of caries, missing teeth due to any other reason, filled teeth with no decay and filled teeth with decayed. None of the children had fissure sealant, Bridge abutment, special crown or Veneer/Implant on primary teeth. None of the children had unerupted tooth, (Crown)/unexposed root on primary teeth.

\section{Dentition status in permanent teeth}

Seventy nine children $(30.74 \%)$ had dental caries in permanent teeth. One $(0.39 \%)$ child had permanent teeth missing as a result of caries. None of the children had permanent teeth missing due to other reason than caries. Two $(0.78 \%)$ children had permanent Filled teeth with no decay. None of the children had permanent filled teeth with decayed and Fissure sealant. None of the children had Bridge abutment, special crown or Veneer/Implant, unerupted tooth, (Crown)/ unexposed root, decayed teeth (root), Filled teeth with no decay (root) and filled teeth with decayed (root). None of the children had Permanent teeth Bridge abutment, special crown or Veneer /Implant (root) and unerupted tooth, (Crown)/unexposed root (root). Seventeen $(6.61 \%)$ children had fractured teeth (Table 1$)$.

\section{Periodontal status}

Out of the total 257 deaf and mute children, 53 (20.62\%), 117 $(45.53 \%), 80(31.13 \%)$ and $7(2.72 \%)$ had healthy periodontium, bleeding on probing, calculus, and periodontal pocket $4-5 \mathrm{~mm}$ respectively and none of the subject had periodontal pocket $6 \mathrm{~mm}$ or more. Loss of attachment (LOA) was recorded only in subject above 15 years of age. LOA $(0-3 \mathrm{~mm})$ was seen in $24(9.34 \%)$ subjects and LOA (4-5 mm) was seen in $4(1.56 \%)$ subjects (Table $2 \mathrm{~A} \& 2 \mathrm{~B})$.

Table 2 (A) Prevalence of periodontal disease (CPI) in deaf and mute children

\begin{tabular}{ll}
\hline $\begin{array}{l}\text { Community Periodontal Index } \\
\text { (CPI) }\end{array}$ & No. (\%) \\
\hline Healthy (0) & $53(20.62)$ \\
Bleeding (I) & $117(45.53)$ \\
Calculus (2) & $80(31.13)$ \\
Pocket 4-5 mm (3)* & $7(2.72)$ \\
Pocket 6 mm or more (4)* & $0(0.00)$ \\
Total & $257(100)$ \\
\hline
\end{tabular}

*Not recorded under the age 15 years.

Table 2 (B) Prevalence of Periodontal disease (LOA) in deaf and mute children

\begin{tabular}{ll}
\hline Loss of Attachment* & No. (\%) \\
\hline $0-3 \mathrm{~mm}$ & $24(9.34)$ \\
$4-5 \mathrm{~mm}$ & $4(1.56)$ \\
Not Recorded & $229(89.10)$ \\
Total & $257(100)$
\end{tabular}

*Not recorded under the age of 15 years. 


\section{Discussion}

All children are not equal, especially when we talk about the special children; their oral health needs special attention as they are the neglected group of our society. Children are a priority group when we plan any oral health programme. It is observed that all children are not considered equal, when normal, healthy children get love and care from their families and society, the subnormal or handicapped children are usually deprived of all the love and affection. Deaf and mute children are also part of such group, because they are deprived of many social benefits in the society. Hence the prevalence of dental caries and periodontal disease in deaf and mute children has drawn the attention of many researchers. In the present study the prevalence of dental caries in primary teeth was $15.18 \%(0.30 \pm 0.83)$ these findings are in agreement with the studies conducted by Doichinova $\mathrm{L}$ et al. ${ }^{22}$ and Jain $\mathrm{M}$ et al. ${ }^{23}$ in which the mean primary decayed teeth were $0.26 \pm 0.88$ and $0.23 \pm 0.76$ respectively. Similarly the prevalence of dental caries in permanent teeth is $30.14 \%(0.54 \pm 0.95)$, These findings are in agreement with study conducted by Mehta A et al., ${ }^{24}$ in which mean permanent decayed teeth were $0.74 \pm 1.37$. The results in the study conducted by Rawlani S et al., ${ }^{25}$ are also in accordance with our study, in which prevalence of dental caries was $35 \%$. However the findings are not in agreement with the study conducted by Jain $\mathrm{M}$ et al., ${ }^{8}$ in which mean decayed primary and permanent teeth were $0.83 \pm 1.60$ and $2.61 \pm 1.74$ respectively. Prevalence of filled teeth (7.14\%) was also found contrary to the present study. ${ }^{8}$ The findings of the study conducted by Avasthi K et al., ${ }^{26}$ reported that dental caries prevalence was $72.43 \%$ and it is contrary to the results obtained in the present study. This could possibly be due to constrains present regarding oral health education \& oral hygiene habits. Other factors could also be due to lack of following proper instruction or commands of parents or caretakers. Another reason is a lack of self-discipline because of overprotective parents. The prevalence of the trauma in permanent teeth was observed in $6.61 \%$ in the present study. There is no similar finding observed however the closest finding is $1 \%$ which is found in study conducted by Vichayanrat $\mathrm{T}$ et al. ${ }^{27}$ The finding of study conducted by Avasthi $\mathrm{K}$ et al., ${ }^{26}$ is not in agreement with the present study in which traumatic dental injuries was recorded $24.48 \%$. This might be due to deaf and mute children had more opportunities to play and move around as compared to other special category children. When periodontal disease status was assessed, Out of the total 257 study subjects, $53(20.62 \%)$ had healthy periodontium and it is supported in study conducted by Bhavasar JP et al. ${ }^{28}$ in which healthy periodontium was reported in $17.1 \%$ subjects. Bleeding on probing was observed in 117 (45.53\%) study subjects in the present study and it is found contrary in the studies conducted by Siddibahvi $\mathrm{MB}^{29}$ and Hamad AM et al., ${ }^{30}$ in which $31.93 \& 20 \%$ subjects had bleeding on probing respectively. In the present study calculus was observed in 80 $(31.13 \%)$ study subjects and it is supported in Siddibahvi $\mathrm{MB}^{29}$ and Vignesha $\mathrm{H}$ et al., ${ }^{31}$ are not in agreement with our findings in which $47.3 \& 40 \%$ calculus was present in the subjects. Periodontal pockets were observed in $7(2.72 \%)$ study subjects in the present study and it is found similar (2.84\%) in study conducted by Siddibhavi MB. ${ }^{29}$ The Community Periodontal Index score was higher due to exogenous factors, which can be divided into primary local factors such as lack of oral hygiene or calculus and secondary local factors such as tongue thrusting, malocclusion and lack of lip seal. The most obvious reason for poor oral hygiene in handicapped children is physical inability to clean the oral cavity adequately.

\section{Limitations of the study}

The study was conducted among 257 deaf and mute children in four special schools in Jaipur city, Rajasthan. Study may be with larger sample size with wide geographical covering can help in extrapolating the results. The study was conducted only in special children with one category i.e. deaf and mute. It could be compared with other special categories and normal counterparts.

\section{Summary and conclusion}

The present study showed high prevalence of decayed teeth in primary and permanent teeth. Very few filled teeth were observed in the study. Almost half of the children had bleeding on probing and around thirty percent had calculus which showed poor periodontal condition. This may be attributed to negligence on the part of parents and authorities of school as their failure to obtained treatment of deaf and mute children. Efforts must be made to encourage parents, caretakers and school teachers to promote and improve their oral health.

\section{Recommendations}

The present study provide data regarding on dental caries and periodontal disease in deaf and mute children in Jaipur city which could form a basis for planning oral health promotive and curative programme for the same. Parents, school teachers should provide oral health education to improve the oral health of this social group. Parents must be given education regarding dental care of their children, dental disease processes, the role of diet in increasing dental caries, and proper oral hygiene measures which are appropriate for children.

\section{Funding}

None.

\section{Acknowledgments}

We are thankful to school authorities and participants for their kind support.

\section{Conflicts of interest}

The author declares there is no conflict of interests.

\section{References}

1. Disabilities. 2015.

2. World health organization. International Classification of Impairments, Disabilities, and Handicaps. A manual of classification relating to the consequences of disease. World health organization. 1980.

3. Gayathri AN. Education of the deaf and mutes. Int $j$ interdiscip res innov 2015;2(6):28-33.

4. Tiwari SK, Khamari J, Kothari S. Impact of Academic Anxiety on Deaf and Dumb Students. Asian J Edu Res \& Tech. 2015;5(1):49-57.

5. Disability and health. 2016

6. Census of India 2011. Data on disability. 2015

7. McDonald RE, Avery DR, Dean JA. Dentistry for the child and adolescent. 2004

8. Jain M, Mathur A, Kumar S, et al. Dentition status and treatment needs among children with impaired hearing attending a special school for the deaf and mute in Udaipur, India. J Oral Sci. 2008;50(2):161-165.

9. Sharma A, Dileep CL, Mathur A, et al. Oral Health Status of intellectually Disabled 3-5 years of Children Attending Special Schools in Rajasthan. IJHSR. 2016;6(2):225-231.

10. Al Ansari AA. Prevalence, Severity, and Secular Trends of Dental Caries among Various Saudi Populations: A Literature Review SJMMS. 2014;2(3):142-150. 
11. Petersen PE, Ogawa H. Strengthening the Prevention of Periodontal Disease: The WHO Approach. J Periodontol. 2005;76(12):87-93.

12. Agarwal V, Khatri M, Singh G, et al. Prevalence of Periodontal Diseases in India. JOHCD. 2010;4:7-16.

13. Khan AA, Jainb SK, Shrivastava A. Prevalence of Dental Caries among the Population of Gwalior (India) in Relation of Different Associated Factors. Eur J Dent. 2008;2(2):81-85.

14. Bhambal A, Chaurasia K, Moon N, et al. A comparison of oral hygiene status and dental caries experience among institutionalized visually impaired and hearing impaired children of age between 7 and 17 years in central India. J Indian Soc Pedo Dent. 2013;31(3):141-145.

15. Suma G, Das UM, Akshatha BS. Dentition Status and Oral Health Practice among Hearing and Speech-Impaired Children: A Cross-sectional Study. J Clin Pediatr Dent. 2011;4(2):105-108.

16. Bhaskar BV, Janakiram C, Joseph J. Access to dental care among differently-abled children in Kochi. J Indian Assoc Public Health Dent. 2016;14(1):29-34.

17. Sanjay V, Shetty SM, Shetty RG, et al. Dental health status among sensory impaired and blind institutionalized children aged 6 to 20 years. J Int Oral Health. 2014;6(1):55-58.

18. Welbury R, Duggal MS, Hosey MT. Pediatric dentistry. Childhood impairment and disability. 4th ed. 2012.

19. Katge F, Rusawat B, Shitoot A, et al. DMFT index assessment, plaque $\mathrm{pH}$ and microbiological analysis in children with special health care needs, India. J Int Soc Prev Community Dent. 2015;5(5):383-388.

20. McHugh ML. Interrater reliability: the kappa statistic Biochem Med (Zagreb). 2012;22(3):276-282.

21. Oral health surveys-basic methods. 4th ed. World Health Organization. 1997.
22. Doichinova L, Peneva M. Prevalence of Dental Caries in Hearing Impaired Children than 5 to 12 Years Old in Sofia. IJSR. 2015;4(1):1088-1091.

23. Jain M, Bharadwaj SP, Kaira LS, et al. Oral Health Status and Treatment Need Among Institutionalized Hearing-Impaired and Blind Children and Young Adults in Udaipur, India. A Comparative Study. OHDM. 2013;12(1):41-49.

24. Mehta A, Gupta R, Mansoob S, et al. Assessment of oral health status of children with special needs in Delhi, India. RSBO. 2015;12(3):244-251.

25. Rawlani S, Rawlani S, Motwani M, et al. Oral Health Status of Deaf and Mute Children Attending Special School in Anand-Wan, Warora, India. $J$ Kor Dent Sci. 2010;3(2):20-25.

26. Awasthi K, Bansal K, Mittal M, et al. Oral health status of sensory impaired children in Delhi and Gurgaon. Int J Dent Clin. 2011;3(2):20-25.

27. Vichayanrat T, Kositpumivate W. Oral health conditions and behaviors among hearing impaired and normal hearing college students at Ratchasuda College, Nakhon Pathom, Thailand. Southeast Asian J Trop Med Public Health. 2014;45(5):1228-1235.

28. Bhavasar JP, Damle SG. Dental caries and oral hygiene amongst 12 14 year old handicapped children of Bombay. J Indian Soc Pedo Dent. $1995 ; 13(1): 1-3$

29. Siddibhavi MB. Oral Health Status of Handicapped Children Attending Various Special Schools in Belgaum City Karnataka. Web med central. 2012;3(2):1-16.

30. Hamad AM, Ali SH, Arif AN, et al. Oral Health Status of Deafness Persons in Sulaimani city-Iraq. IOSR-JDMS. 2015;14(9):69-73.

31. Vignesha H, Soh G, Lo GL, et al. Dental health of the disabled children in Singapore. Aust Dent J. 1991;36(2):151-156. 